\title{
Factors associated with changes in adequate antenatal care visits among pregnant women aged 15-49 years in Tanzania from 2004 to 2016
}

Elizabeth Kasagama ${ }^{1 *} \mathbb{D}$, Jim Todd ${ }^{2}$ and Jenny Renju²

\begin{abstract}
Background: Antenatal care (ANC) is crucial for the health of the mother and unborn child as it delivers highly effective health interventions that can prevent maternal and newborn morbidity and mortality. In 2002, the World Health Organization (WHO) recommended a minimum of four ANC visits for a pregnant woman with a positive pregnancy during the entire gestational period. Tanzania has sub-optimal adequate (four or more) ANC visits, and the trend has been fluctuating over time. An understanding of the factors that have been contributing to the fluctuating trend over years is pivotal in increasing the proportions of pregnant women attaining adequate ANC visits in Tanzania.

Methods: The study used secondary data from Tanzania Demographic Health Survey (TDHS) from 2004 to 2016. The study included 17976 women aged 15-49 years. Data were analyzed using Stata version 14. Categorical and continuous variables were summarized using descriptive statistics and weighted proportions. A Poisson regression analysis was done to determine factors associated with adequate ANC visits. To determine factors associated with changes in adequate ANC visits among pregnant women in Tanzania from 2004 to 2016, multivariable Poisson decomposition analysis was done.
\end{abstract}

Results: The overall proportion of women who had adequate ANC visits in 2004/05, 2010 and 2015/16 was 62, 43 and 51\% respectively. The increase in the proportion of women attaining adequate ANC from 2010 to 2015/16 was mainly, 66.2\% due to changes in population structure, thus an improvement in health behavior. While $33.8 \%$ was due to changes in the mother's characteristics. Early initiation of first ANC visit had contributed $51 \%$ of the overall changes in adequate ANC attendance in TDHS 2015/16 survey.

Conclusion: Early ANC initiation has greatly contributed to the increased proportion of pregnant women who attain four or more ANC visits overtime. Interventions on initiating the first ANC visit within the first twelve weeks of pregnancy should be a priority to increase proportion of women with adequate ANC visit.

Keywords: Antenatal care, Adequate ANC, Changes, Maternal health, Maternal mortality, Tanzania

*Correspondence: kasagamae93@gmail.com

1 Department of Epidemiology and Biostatistics, Institute of Public Health, Kilimanjaro Christian Medical University College (KCMUCo), P.O Box 2240, Kilimanjaro, Tanzania

Full list of author information is available at the end of the article

\begin{abstract}
Background
Adequate and quality antenatal care (ANC) is effective at promoting better health outcomes for both mother and child during pregnancy [1,2]. Strong evidence exists to support the link between ANC during pregnancy, skilled birth attendants during delivery, and quality postnatal care and reduced maternal and infant morbidity and mortality [3-8]. Globally, almost $60 \%$ of stillbirths
\end{abstract}

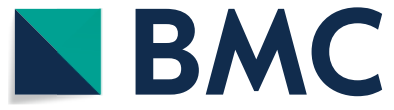

(c) The Author(s) 2022. Open Access This article is licensed under a Creative Commons Attribution 4.0 International License, which permits use, sharing, adaptation, distribution and reproduction in any medium or format, as long as you give appropriate credit to the original author(s) and the source, provide a link to the Creative Commons licence, and indicate if changes were made. The images or other third party material in this article are included in the article's Creative Commons licence, unless indicated otherwise in a credit line to the material. If material is not included in the article's Creative Commons licence and your intended use is not permitted by statutory regulation or exceeds the permitted use, you will need to obtain permission directly from the copyright holder. To view a copy of this licence, visit http://creativecommons.org/licenses/by/4.0/. The Creative Commons Public Domain Dedication waiver (http://creativeco $\mathrm{mmons}$.org/publicdomain/zero/1.0/) applies to the data made available in this article, unless otherwise stated in a credit line to the data. 
are due to poor fetal growth, untreated and unattended maternal infection, and conditions that could have been avoided or treated by expert attention during ANC visits [7]. A wide range of services can be offered during ANC including screening, detection, prevention and treatment of any pregnancy-related complication, infection or morbidity [9].

The WHO 2002 Focus Antenatal Care (FANC) model recommends a minimum of four ANC visits for a woman with an uncomplicated pregnancy, with the first visit occurring during the first twelve weeks of pregnancy, although currently there is an 8-contact model in place $[9,10]$. In 2002, Tanzania adopted FANC, however, the first ANC is to be initiated within 16 gestational weeks [11]. Globally, ANC coverage (at least one visit during pregnancy) is $86 \%$, yet only $62 \%$ of women meet the recommended four ANC visits. In Africa, ANC coverage is $69 \%$ with only $54 \%$ of women attending the minimum of four ANC visits, while in Tanzania, ANC coverage is higher, $98 \%$ but only $51 \%$ of pregnant women attain the minimum of four ANC visits [12]. Despite high ANC coverage, adequate (four or more) ANC visits are still suboptimal and could partly explain the unacceptably high neonatal mortality and stillbirth rates in Tanzania, with 25 deaths/1000 live births and 39 deaths/1000 pregnancies, respectively [13].

To scale up the uptake of ANC and to address the burden of maternal mortality, additional interventions were introduced. These included Exemptions from paying user fees on health care services for maternal, newborn and child under five. In 2012, Tanzania's National Safe Motherhood Campaign (Wazazi Nipendeni) was implemented to encourage pregnant women to initiate the first ANC within 12 weeks of pregnancy and adhere to ANC services [14]. In 2014, the "Big Results Now" and the "Sharpened One Plan" programs were implemented. Despite these interventions, the Tanzania Demographic and Health Survey (TDHS) reported a fluctuating trend in adequate ANC visits: a fall from 62 to $43 \%$ and a rise to $51 \%$ for $2004 / 05,2010$ and 2015/16 surveys, respectively [13]. This suboptimal ANC attendance has been associated with a several factors, as documented in various studies worldwide. The factors include but are not limited to: long distance to a health facility, geographical zone, first ANC initiation, woman's desire to avoid pregnancy, marital status, wealth quintiles, multiparity, living in an urban area, and higher education level [14-19].

This study aimed to show how much each individual factor has contributed to the decline from 2004/04 to 2010 and the increase from 2010 to $2015 / 16$ in the TDHS and how they have contributed to the varying low proportions of adequate ANC visits over time. Filling this knowledge gap may help identify the key contributing factors and provide valuable information on how the programmatic changes during the 2004-2016 period have impacted adequate ANC attendance. Moreover, understanding the factors associated with changes in adequate ANC visits may help to provide useful information to policymakers, project implementing partners and in designing target interventions that may improve adequate ANC visits in Tanzania.

\section{Methods}

\section{Study design and study settings}

The study was conducted in Tanzania, which includes the mainland and island. This was a Crossectional study that used data from the Tanzania Demographic Health Survey (TDHS), Further details of the survey are available elsewhere [13], but in brief this is a national representative survey done after five years with the objective to obtain the current and reliable information on demographic and health indicators about family planning, fertility levels and preferences, maternal mortality, infant and child mortality, nutritional status of mothers and children, ANC, delivery care, and childhood immunizations and diseases. Data were obtained from www.dhsprogram. com, after being granted permission to access and use TDHS data. Data from 2004/04, 2010 and 2015/16 surveys were used.

\section{Study population}

The population was all women of reproductive age (1549 years) who had given birth to at least one child within the five years before the survey and had information on ANC visits. For a woman with multiple births during the five-year period, we considered mother's last birth within 5 years prior the survey for this analysis. A total of 33,734 women aged 15-49 years in Tanzania participated in the three TDHS surveys. After excluding those with missing information on ANC visits, we remained with a total of 17,976 . Of 17,976 women enrolled in the study: 4541(77.9\%), 4201(76.9\%) and 5193(70.1\%) for 2004/05, 2010 and 2015/16 surveys respectively (Fig. 1).

\section{Study variables}

Our dependent variable was adequate ANC visits, which was categorized as four or more ANC visits and coded 1, less than four ANC visits as inadequate were coded 0 . Independent variables were respondent's age at last birth (15-19 years, 20-24 years, $25-29$ years, $30-34$ years, $35+$ years), education level (no formal education, primary education, secondary and higher education), employment status (unemployed, employed), marital status (married/cohabiting, single, divorced/widowed/ separated), residence (urban, rural), wealth index (poorest, poorer, middle, richer, richest), zones; these are 


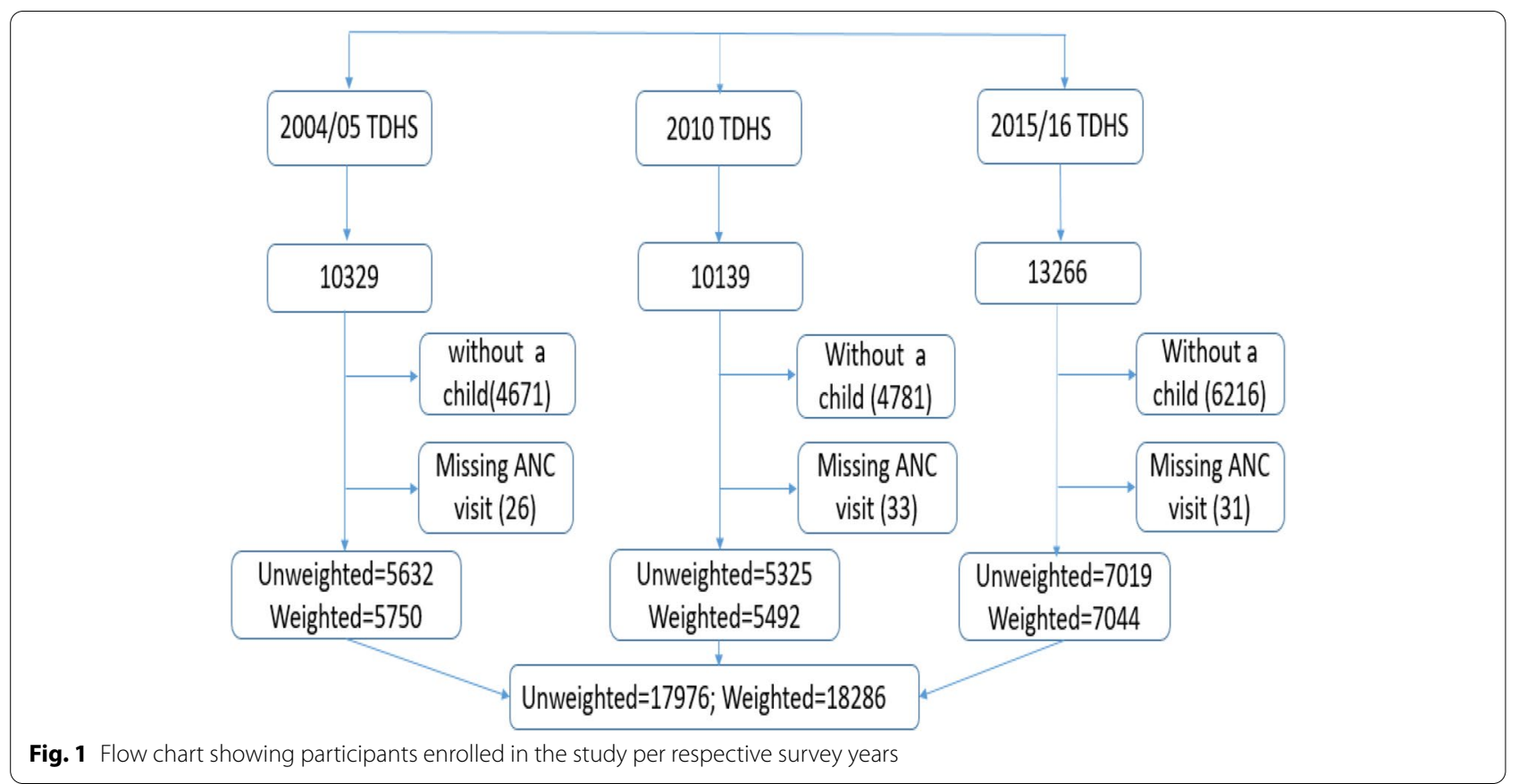

administrative regions grouped according to geographical location (western zone, northern zone, central zone, southern highlands, southern zone, south west highlands zone, lake zone, eastern zone, Zanzibar), first ANC initiated (women with first ANC visit later than 12 gestational weeks, women with first ANC visit by 12 gestational weeks), decision maker of respondent's health care (respondent alone, respondent and partner, partner alone, someone else), parity ( 1 child, $2-3$ children, 4-5 children, 6 or more children), frequency of listening to radio (not at all, Less than once a week, at least once a week), frequency of watching TV (not at all, less than once a week, at least once a week), desire of last pregnancy (wanted then, wanted later, wanted no more), history of terminated pregnancy (never had, ever had) and distance from health facility (big problem, not a big problem). The selection of variables was made using the Andersen's Behavioural Model of Health Services Use [20]. All these variables were considered as mother's characteristics and population characteristics in the analysis.

\section{Statistical analysis}

Data were analyzed using STATA Corporation, College Station, TX, USA version 14 (Stata/SE 14.2). The analysis considered the complex survey features: primary sampling units, strata, and sampling weights. A Poisson regression analysis was done to determine factors associated with adequate ANC visits. Multivariable Poisson decomposition analysis was conducted to determine factors associated with changes in adequate ANC visits. Decomposition analysis was conducted to understand whether observed changes in adequate ANC visits could be explained by changes in factors over time or in the population structure (population dynamics). To explain the observed change in the percentage of pregnant women attaining adequate ANC visits, we used the Blinder-Oaxaca decomposition analysis [21-23]. The main goal decomposition analysis was to explain on the individual contributions of the factors on adequate ANC visits differences among pregnant women in Tanzania in different surveys. The differentials in adequate ANC visits between these groups was portioned into two components, one that can be attributable to differences in characteristics and the component that is attributable to the effect of those characteristics. The factors might have a different contribution on the change observed at different survey period. The decomposition analysis was done between two time points, at first, we decomposed survey year 2004/05 to 2010 and lastly survey year 2015/16 to 2010 . The baseline survey year was the one with the lowest proportion of pregnant women with adequate ANC visits, thus survey year 2010 for both decomposition analysis. Contributions were considered statistically significant at a $P$-value of less than 0.05 .

\section{Results}

Characteristics of the study participants

A total of 17,976 women were included in the analysis. Most of the participants were from rural areas, the mean 
age $( \pm \mathrm{SD})$ of the study population was $27.06( \pm 7.00)$. More than half of the respondents in each survey had at least primary education level. Most of the participants were married or cohabiting: $85.4,84.2$ and $81.6 \%$ for 2004/05, 2010 and 2015/16 survey, respectively. The proportions of women aged 35 to 45 years increased across the survey years, from $15.6 \%$, in $2004 / 05$ to $17.8 \%$ in $2015 / 16$. The percentage of women who achieved secondary education and above also increased from $9.2 \%$ in $2004 / 05$ to $19.9 \%$ in $2015 / 16$ and the percentage of women without formal education decreased from $26.8 \%$ in $2004 / 05$ to $19.5 \%$ in $2015 / 16$. Substantial regional variation in survey participation was observed; throughout the three surveys, the Lake Zone had the highest percentage of women participating in the survey while the Southern zone had lowest (Table 1).

Table 1 Characteristics of the study participants $(N=17976)$

\begin{tabular}{|c|c|c|c|}
\hline \multirow[t]{2}{*}{ Variables } & \multirow{2}{*}{$\begin{array}{l}2004-05 \text { TDHS } \\
\text { Frequency }(\%)(n=5632)\end{array}$} & \multirow{2}{*}{$\begin{array}{l}2010 \text { TDHS } \\
\text { Frequency (\%) } \\
(n=5325)\end{array}$} & \multirow{2}{*}{$\begin{array}{l}\text { 2015-16 TDHS } \\
\text { Frequency (\%) } \\
(n=7019)\end{array}$} \\
\hline & & & \\
\hline \multicolumn{4}{|l|}{ Age at delivery (in years) } \\
\hline $15-19$ & $961(17.1)$ & $775(14.5)$ & 1253(17.8) \\
\hline $20-24$ & $1532(27.2)$ & $1376(25.8)$ & 1733(24.7) \\
\hline $25-29$ & $1326(23.5)$ & $1249(23.5)$ & 1593(22.7) \\
\hline $30-34$ & $933(16.6)$ & $940(17.7)$ & 1194(17.0) \\
\hline $35+$ & $880(15.6)$ & $985(18.5)$ & $1246(17.8)$ \\
\hline Mean age $( \pm S D)$ & $27.1( \pm 7.07)$ & $27.80( \pm 7.10)$ & $27.41( \pm 7.23)$ \\
\hline \multicolumn{4}{|l|}{ Zones } \\
\hline Western zone & $522(9.3)$ & $502(9.4)$ & 619(8.8) \\
\hline Northern zone & $546(9.7)$ & 489(9.2) & $562(8.0)$ \\
\hline Central zone & $676(12.0)$ & $625(11.7)$ & $690(9.8)$ \\
\hline Southern Highlands & $399(7.1)$ & $366(6.9)$ & $561(8.0)$ \\
\hline Southern zone & $368(6.5)$ & $342(6.4)$ & $347(4.9)$ \\
\hline Southwest Highlands zone & 499(8.9) & $410(7.7)$ & $778(11.1)$ \\
\hline Lake Zone & $1051(18.7)$ & $1020(19.2)$ & $1803(25.7)$ \\
\hline Eastern zone & $522(9.3)$ & $534(10.0)$ & $713(10.2)$ \\
\hline Zanzibar & 1049(18.5) & $1037(19.5)$ & $946(13.5)$ \\
\hline \multicolumn{4}{|l|}{ Place of residence } \\
\hline Rural & $4541(80.6)$ & $4201(78.9)$ & 5193(74.0) \\
\hline Urban & 1091(19.4) & $1124(21.1)$ & $1826(26.0)$ \\
\hline \multicolumn{4}{|l|}{ Highest level of education } \\
\hline No formal education & $1509(26.8)$ & $1262(23.7)$ & $1368(19.5)$ \\
\hline Primary education & $3603(64.0)$ & 3393(63.7) & 4255(60.6) \\
\hline Secondary and above & $520(9.2)$ & $670(12.6)$ & 1396(19.9) \\
\hline \multicolumn{4}{|l|}{ Current marital status } \\
\hline Single & $285(5.0)$ & $296(5.6)$ & $451(6.4)$ \\
\hline Married/Cohabiting & $4809(85.4)$ & $4486(84.2)$ & 5724(81.6) \\
\hline Widowed/Divorced/Separated & $538(9.6)$ & $543(10.2)$ & $844(12.0)$ \\
\hline \multicolumn{4}{|l|}{ Employment status $^{\mathrm{ab}}$} \\
\hline Unemployed & 1029(18.3) & $929(17.5)$ & 1515(21.6) \\
\hline Employed & $4602(81.7)$ & $4388(82.5)$ & $5504(78.4)$ \\
\hline \multicolumn{4}{|l|}{ Wealth index } \\
\hline Poorest & $1167(20.7)$ & 1006(18.9) & $1441(20.5)$ \\
\hline Poorer & $1131(20.1)$ & $1150(21.6)$ & 1356(19.3) \\
\hline Middle & 1082(19.2) & 1078(20.2) & 1376(19.6) \\
\hline Richer & $1247(22.1)$ & $1161(21.8)$ & 1544(22.0) \\
\hline Richest & 1005(17.9) & $930(17.5)$ & 1302(18.6) \\
\hline
\end{tabular}

a Employment status 2004/5 $(n=5631)$

${ }^{\mathrm{b}}$ Employment status $2010(n=5317)$ 


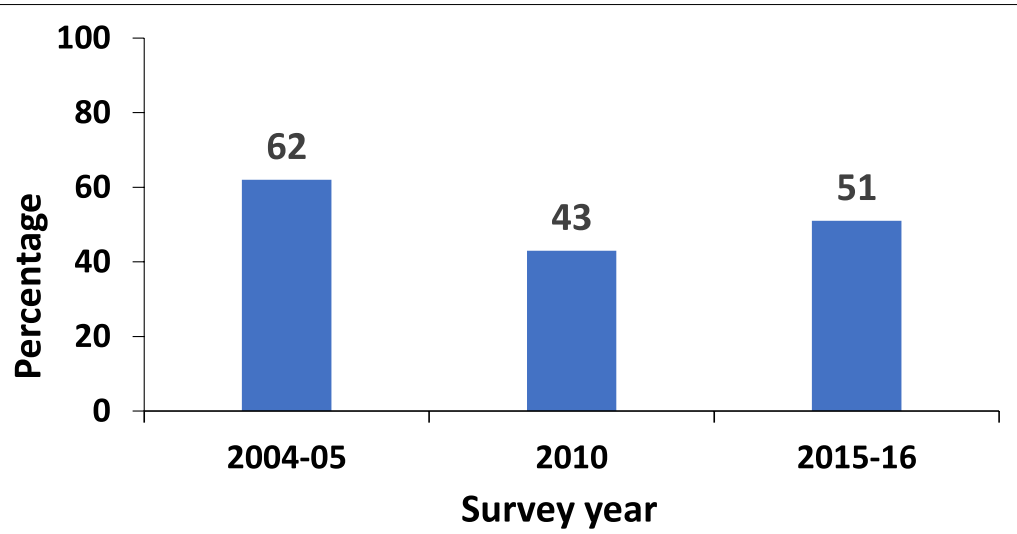

Fig. 2 Percentage of pregnant women with adequate ANC visits from 2004 to 2016

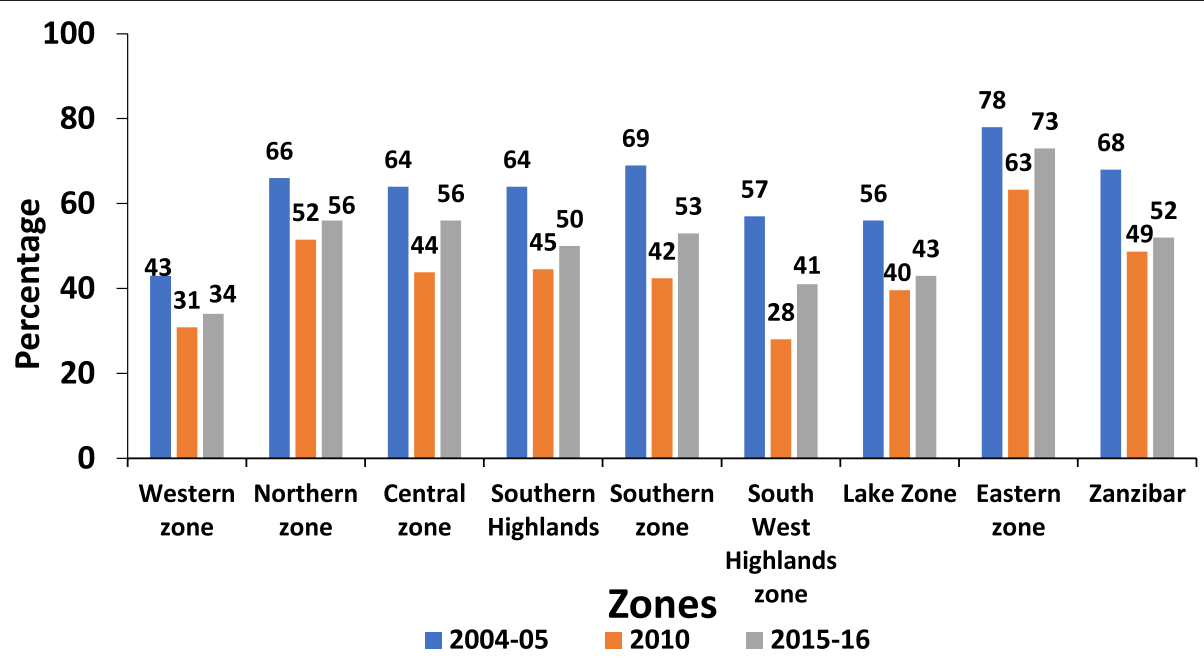

Fig. 3 Percentage of pregnant women with adequate ANC visits by zones in Tanzania from 2004 to 2016

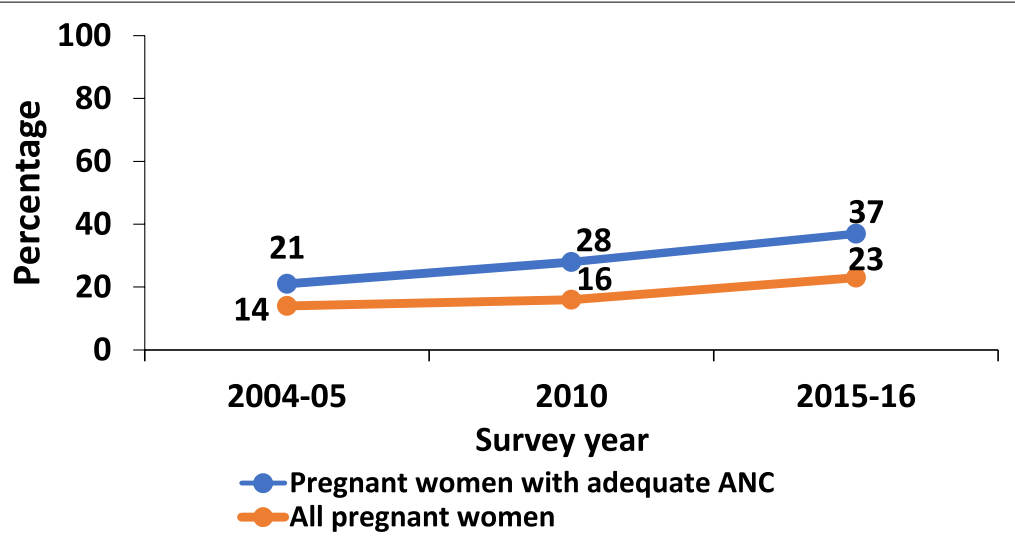

Fig. 4 Percentage of pregnant women with first ANC visit in first trimester from 2004 to 2016 
Table 2 Factors associated with adequate antenatal care visits in Tanzania

\begin{tabular}{llll}
\hline Characteristics & 2004-05 TDHS & 2010 TDHS & 2015-16 TDHS \\
& APR $(95 \% \mathrm{Cl})$ & APR $(95 \% \mathrm{Cl})$ & APR $(95 \% \mathrm{Cl})$
\end{tabular}

\begin{tabular}{llll}
\hline \multicolumn{2}{l}{ Age at delivery (in years) } & & \\
$15-19$ & 1 & 1 & 1 \\
$20-24$ & $0.92(0.85-0.99)$ & $1.21(1.05-1.40)$ & $1.06(0.96-1.18)$ \\
$25-29$ & $0.95(0.87-1.04)$ & $1.21(1.03-1.42)$ & $1.04(0.93-1.17)$ \\
$30-34$ & $0.95(0.85-1.06)$ & $1.45(1.20-1.74)$ & $1.15(1.01-1.30)$ \\
$35+$ & $0.96(0.85-1.09)$ & $1.28(1.03-1.58)$ & $1.19(1.02-1.38)$
\end{tabular}

Zones

\begin{tabular}{|c|c|c|c|}
\hline Western zone & 1 & 1 & 1 \\
\hline Northern zone & $1.47(1.31-1.66)$ & $1.45(1.19-1.77)$ & $1.52(1.31-1.76)$ \\
\hline Central zone & $1.50(1.34-1.69)$ & $1.37(1.13-1.66)$ & $1.71(1.48-1.98)$ \\
\hline $\begin{array}{l}\text { Southern High- } \\
\text { nds }\end{array}$ & $1.37(1.21-1.56)$ & $1.11(0.89-1.38)$ & $1.25(1.07-1.46)$ \\
\hline Southern zone & $1.49(1.32-1.69)$ & $1.16(0.93-1.45)$ & $1.30(1.10-1.54)$ \\
\hline $\begin{array}{l}\text { Southwest High- } \\
\text { inds }\end{array}$ & $1.40(1.23-1.58)$ & $0.74(0.58-0.96)$ & $1.25(1.05-1.49)$ \\
\hline Lake Zone & $1.29(1.15-1.44)$ & $1.27(1.06-1.53)$ & $1.47(1.28-1.68)$ \\
\hline Eastern zone & $1.62(1.44-1.81)$ & $1.53(1.26-1.85)$ & $1.71(1.49-1.97)$ \\
\hline Zanzibar & $1.46(1.31-1.63)$ & $1.27(1.05-1.53)$ & $1.48(1.28-1.72)$ \\
\hline \multicolumn{4}{|l|}{ lace of residence } \\
\hline Rural & $1.00(0.94-1.08)$ & $0.98(0.87-1.11)$ & $0.93(0.85-1.01)$ \\
\hline Urban & 1 & 1 & 1 \\
\hline \multicolumn{4}{|c|}{ lighest level of education } \\
\hline $\begin{array}{l}\text { No formal educa- } \\
\text { on }\end{array}$ & 1 & 1 & 1 \\
\hline Primary education & 1.04(0.98-1.10) & $1.13(1.01-1.26)$ & $1.05(0.96-1.14)$ \\
\hline $\begin{array}{l}\text { Secondary and } \\
\text { bove }\end{array}$ & 1.09(0.99-1.20) & $1.25(1.06-1.48)$ & $1.12(1.01-1.25)$ \\
\hline \multicolumn{4}{|l|}{ arity } \\
\hline 1 & 1 & 1 & 1 \\
\hline $2-3$ & $0.98(0.92-1.05)$ & $0.89(0.78-1.02)$ & $0.88(0.81-0.96$ \\
\hline $4-5$ & $0.99(0.92-1.06)$ & $0.76(0.64-0.91)$ & $0.83(0.74-0.94)$ \\
\hline $6+$ & $0.95(0.87-1.03)$ & $0.74(0.60-0.92)$ & $0.78(0.67-0.91)$ \\
\hline
\end{tabular}

Decision maker on respondent's health

\begin{tabular}{|c|c|c|c|}
\hline Respondent alone & 1 & 1 & 1 \\
\hline $\begin{array}{l}\text { Respondent and } \\
\text { artner }\end{array}$ & $0.94(0.88-1.00)$ & $0.93(0.83-1.03)$ & 1.05(0.97-1.13) \\
\hline Partner alone & $0.96(0.91-1.01)$ & $0.87(0.78-0.98)$ & $0.93(0.87-1.03)$ \\
\hline Someone else & $0.89(0.80-0.99)$ & $0.89(0.58-1.37)$ & $1.02(0.62-1.68)$ \\
\hline \multicolumn{4}{|c|}{ esire of last pregnancy } \\
\hline Wanted then & 1 & 1 & 1 \\
\hline Wanted later & $0.96(0.90-1.02)$ & $0.82(0.74-0.92)$ & $0.92(0.86-0.98)$ \\
\hline Wanted no more & $0.95(0.86-1.06)$ & $1.06(0.85-1.31)$ & $0.93(0.78-1.11)$ \\
\hline \multicolumn{4}{|l|}{ Vealth index } \\
\hline Poorest & 1 & 1 & 1 \\
\hline Poorer & $1.08(1.00-1.17)$ & 0.95(0.83-1.09) & 1.03(0.93-1.14) \\
\hline Middle & $1.07(0.99-1.16)$ & $1.03(0.90-1.17)$ & $1.05(0.95-1.16)$ \\
\hline Richer & $1.12(1.03-1.21)$ & $1.18(1.03-1.35)$ & $1.22(1.11-1.35)$ \\
\hline Richest & $1.16(1.05-1.27)$ & $1.10(0.93-1.31)$ & $1.16(1.02-1.31)$ \\
\hline
\end{tabular}

Table 2 (continued)

\begin{tabular}{|c|c|c|c|}
\hline Characteristics & $\begin{array}{l}\text { 2004-05 TDHS } \\
\text { APR }(95 \% \mathrm{Cl})\end{array}$ & $\begin{array}{l}2010 \text { TDHS } \\
\text { APR }(95 \% \mathrm{Cl})\end{array}$ & $\begin{array}{l}2015-16 \text { TDHS } \\
\text { APR }(95 \% \mathrm{Cl})\end{array}$ \\
\hline \multicolumn{4}{|l|}{ First ANC initiated } \\
\hline $\begin{array}{l}\text { Later than } 1^{\text {st }} \\
\text { trimester }\end{array}$ & 1 & 1 & 1 \\
\hline Within $1^{\text {st }}$ trimester & $1.47(1.41-1.52)$ & $1.96(1.82-2.11)$ & $1.89(1.79-2.00)$ \\
\hline \multicolumn{4}{|c|}{ Distance to Health facility } \\
\hline Not a big problem & $1.06(1.01-1.12)$ & $1.03(0.93-1.14)$ & 1.05(0.99-1.11) \\
\hline Big problem & 1 & 1 & 1 \\
\hline \multicolumn{4}{|c|}{ Frequency of watching TV } \\
\hline Not at all & 1 & 1 & 1 \\
\hline $\begin{array}{l}\text { Less than once a } \\
\text { week }\end{array}$ & $1.04(0.97-1.12)$ & $1.03(0.91-1.17)$ & $0.99(0.92-1.08)$ \\
\hline $\begin{array}{l}\text { At least once a } \\
\text { week }\end{array}$ & $1.01(0.93-1.08)$ & $1.24(1.09-1.42)$ & 1.05(0.96-1.16) \\
\hline
\end{tabular}

\section{Trends of adequate antenatal care visits}

The trend in adequate ANC attendance has fluctuated over time. Adequate ANC attendance decreased from $61 \%$ in $2004 / 05$ to $43 \%$ in the 2010 survey and then increased again to $51 \%$ in the $2015 / 16$ survey (Fig. 2). A similar pattern was also found when stratified by geographical zone. The eastern zone had the highest percentage of women with adequate ANC attendance for all three surveys (Fig. 3). The percentage of women with four ANC visits who initiated their first ANC visit in the first trimester increased over time (Fig. 4).

\section{Factors associated with adequate antenatal care visits}

Various factors were associated with adequate ANC visits for each survey, including first ANC in the first trimester, multiparity, wanting pregnancy later, watching TV at least once a week, older age, geographical zone, secondary education and above, reasonable distance to a health facility, richer and richest household wealth index (Table 2).

In the multivariable Poisson regression analysis, for all three surveys ANC initiation within the first trimester had a positive effect on adequate ANC visits. The proportion of women with adequate ANC attendance was 1.47 (95\% CI: 1.41-1.52) times greater among women who initiated ANC within the first trimester compared to those who initiated later in the 2004/05 survey, 1.96 (95\% CI: 1.82-2.11) times higher in 2010, and 1.89 (95\% CI: 1.792.00 ) times higher in $2015 / 16$. However, wanting pregnancy later had a negative influence on adequate ANC visits. In the 2004/05 survey, adequate ANC attendance was 0.96 (95\% CI: 0.90-1.02) times lower among women who wanted pregnancy later compared to those who wanted pregnancy at that time, 0.82 (95\% CI: 0.74-0.92) 
Table 3 Decomposition of changes in adequate antenatal care visits 2004 to 2010

\begin{tabular}{|c|c|c|c|c|c|c|}
\hline \multirow[t]{2}{*}{ Characteristics } & \multicolumn{3}{|c|}{ Differences in Population structure (E) } & \multicolumn{3}{|c|}{ Differences in coefficients $(C)$} \\
\hline & Coefficient & $\%$ & $p$-value & Coefficient & $\%$ & $p$-value \\
\hline \multicolumn{7}{|l|}{ Age at delivery (in years) } \\
\hline $15-19$ & 1.0 & & & 1.0 & & \\
\hline $20-24$ & 0.0015 & -0.7 & 0.352 & 0.0345 & -16.3 & 0.001 \\
\hline $25-29$ & -0.0007 & -0.3 & 0.709 & 0.0232 & -11.1 & 0.013 \\
\hline $30-34$ & -0.0026 & 1.2 & 0.707 & 0.0284 & -13.4 & $<0.001$ \\
\hline $35+$ & -0.0038 & 1.8 & 0.707 & 0.0148 & -7 & 0.065 \\
\hline \multicolumn{7}{|l|}{ Zones } \\
\hline Western zone & 1.0 & & & 1.0 & & \\
\hline Northern zone & -0.0035 & 1.7 & 0.711 & -0.0008 & 0.4 & 0.865 \\
\hline Central zone & -0.0012 & 0.6 & 0.711 & -0.0045 & 2.1 & 0.431 \\
\hline Southern Highlands & -0.0001 & 0.1 & 0.73 & -0.0074 & 3.5 & 0.083 \\
\hline Southern zone & 0.0002 & -0.1 & 0.729 & -0.0071 & 3.3 & 0.037 \\
\hline Southwest Highlands & -0.0008 & 0.4 & 0.71 & -0.0301 & 14.2 & $<0.001$ \\
\hline Lake Zone & 0.0033 & -1.6 & 0.713 & -0.0014 & 0.7 & 0.941 \\
\hline Eastern zone & 0.0029 & -1.4 & 0.711 & -0.0042 & 2 & 0.551 \\
\hline Zanzibar & -0.0005 & 0.2 & 0.713 & -0.0014 & 0.7 & 0.291 \\
\hline \multicolumn{7}{|l|}{ Highest level of education } \\
\hline No formal education & 1.0 & & & 1.0 & & \\
\hline Primary education & 0.0014 & -0.7 & 0.713 & 0.0197 & -9.3 & 0.34 \\
\hline Secondary and above & -0.0014 & 0.7 & 0.709 & 0.002 & -0.9 & 0.448 \\
\hline \multicolumn{7}{|l|}{ Parity } \\
\hline 1 child & 1.0 & & & 1.0 & & \\
\hline 2-3 children & -0.0004 & 0.2 & 0.745 & -0.0136 & 6.5 & 0.121 \\
\hline 4-5 children & 0.0039 & -1.9 & 0.721 & -0.0195 & 9.2 & 0.04 \\
\hline $6+$ children & 0.001 & -0.5 & 0.717 & -0.0175 & 8.2 & 0.096 \\
\hline \multicolumn{7}{|l|}{ Wealth index } \\
\hline Poorest & 1.0 & & & 1.0 & & \\
\hline Poorer & 0.0041 & -1 & 0.745 & -0.0121 & 5.7 & 0.111 \\
\hline Middle & -0.0001 & 0.05 & 0.792 & -0.004 & 1.9 & 0.588 \\
\hline Richer & -0.0002 & 0.1 & 0.714 & 0.0035 & -1.6 & 0.644 \\
\hline Richest & -0.0001 & 0.03 & 0.919 & -0.0127 & 6 & 0.865 \\
\hline \multicolumn{7}{|c|}{ Decision on respondent's health } \\
\hline Respondent alone & 1.0 & & & 1.0 & & \\
\hline Respondent \& partner & 0.0136 & -6.4 & 0.759 & -0.0006 & 0.3 & 0.898 \\
\hline Partner alone & 0.0042 & -2 & 0.738 & -0.0126 & 5.9 & 0.21 \\
\hline Someone else & -0.0028 & 1.3 & 0.743 & 0.0002 & -0.1 & 0.96 \\
\hline \multicolumn{7}{|l|}{ Desire of last pregnancy } \\
\hline Wanted then & 1.0 & & & 1.0 & & \\
\hline Wanted later & 0.0022 & -1.1 & 0.712 & -0.0122 & 5.7 & 0.028 \\
\hline Wanted no more & 0.0004 & -0.2 & 0.775 & 0.026 & -1.2 & 0.41 \\
\hline \multicolumn{7}{|l|}{ First ANC initiated } \\
\hline Later than $1^{\text {st }}$ trimester & 100 & & & 1.0 & & \\
\hline Within $1^{\text {st }}$ trimester & -0.0016 & 0.7 & 0.352 & -0.0188 & -8.7 & $<0.001$ \\
\hline \multicolumn{7}{|l|}{ Distance to Health facility } \\
\hline Big problem & 1.0 & & & 1.0 & & \\
\hline Not a big problem & -0.0034 & 1.6 & 0.692 & -0.0086 & 4.1 & 0.58 \\
\hline \multicolumn{7}{|l|}{ Frequency of watching TV } \\
\hline Not at all & 1.0 & & & 1.0 & & \\
\hline
\end{tabular}


Table 3 (continued)

\begin{tabular}{|c|c|c|c|c|c|c|}
\hline \multirow[t]{2}{*}{ Characteristics } & \multicolumn{3}{|c|}{ Differences in Population structure (E) } & \multicolumn{3}{|c|}{ Differences in coefficients $(C)$} \\
\hline & Coefficient & $\%$ & $p$-value & Coefficient & $\%$ & $p$-value \\
\hline Less than once a week & 0.0004 & -0.02 & 0.759 & -0.0001 & -0.01 & 0.984 \\
\hline At least once a week & 0.0040 & 1.9 & 0.706 & 0.012 & -5.7 & 0.013 \\
\hline Constant & & & & -0.1929 & 60.8 & 0.004 \\
\hline Total & & 4.2 & 0.352 & & 95.8 & $<0.001$ \\
\hline
\end{tabular}

times lower in 2010, and 0.92 (95\% CI: 0.86-0.98) times lower in 2015/16 (Table 2).

\section{Factors associated with changes in adequate antenatal care visits across the surveys}

The multivariable decomposition regression models found that $95.8 \%$ of the decline in adequate ANC visits from 2004/05 (62\%) to 2010 (43\%) were attributed by changes in the coefficients (mother's characteristics) and only $4.2 \%$ of the decline was due to changes in the population characteristics (population dynamics). There were no significant changes in the population structures during this period, suggesting that the population remained relatively static between the 2004/05 and 2010 surveys. The southwest highland zone contributed 14.2\% to the observed decline in the 2004/05 and 2010 surveys, which was statistically significant. It means that the zone where a pregnant woman lived affected her ability to attain adequate ANC. Changes in the initiation of the first ANC within the first trimester slowed the decline by $8.7 \%$, which was also statistically significant (Table 3 ).

The proportion of women attaining adequate ANC increased from $43 \%$ in 2010 to $51 \%$ in $2015 / 16$. The slight increase was attributed to $33.8 \%$ of changes due to the coefficients and $66.2 \%$ due to the changes in the population characteristics. These changes were statistically significant with a $p$-value of $<0.001$. The increase in the proportion of women who initiated ANC during the first trimester contributed $50.5 \%$ to the increase observed in 2010 to $2015 / 16$ surveys. This was statistically significant at a $p$-value of $<0.001$. In the contributions due to differences in coefficients, the southwest highlands contributed $21.4 \%$ to the overall increase (Table 4 ).

\section{Discussion}

The study findings for all the three surveys suggest that women who had their first ANC visit within the first 12 weeks of pregnancy were more likely to achieve adequate ANC visits. These findings are consistent with other studies done in Tanzania, Peru, Cambodia, Cameroon, Senegal, Uganda and Nepal $[24,25]$. This similarity can be explained by various interventions that have been conducted in the mentioned countries on ANC utilization as well as early initiation of ANC visits among pregnant women. This positive association between early ANC initiation and adequate ANC visits has also been reported in many other literatures.

The decomposition analysis suggests that changes in population structure and the effects contributed to the variations in adequate ANC visits overtime. Furthermore, the Tanzania Service Provision Assessment Survey reported on differentials in the quality and availability of health care services offered across regions [26]. In some ways, this can explain the decline observed in the 2004/05 and 2010 surveys. Also, time interval between the two surveys which was a transitional stage in maternal health care as Tanzania adopted FANC in 2002, and challenges in the rollout of the new intervention. Although, we cannot overlook the role of quality of ANC services offered, as it has been documented that poor quality could negatively affect ANC attendance. This may have contributed to the decline observed, although this study was unable to address this [11, 25, 27, 28].

For the 2010 and 2015-16 surveys, the first ANC within the first trimester attributed $50.5 \%$ of the increase in the proportion of women wo attained adequate ANC visits to differences due to population structure. Efforts to ensure Tanzania reached the MDG 4 and 5 by 2015 and "Wazazi Nipendeni campaign" in 2012 could explain the increase in adequate ANC attendance in 2010 and 2016 $[14,16]$. For the southwest highlands, the increase in the proportion of pregnant women with adequate ANC visits could be attributed to the Wazazi na Mwana campaign in 2 councils in Rukwa one of the regions included in the zone $[29,30]$. While it is not possible to directly attribute the impact of these campaigns, they likely played a part in the observed increase in early ANC initiation, which is a contributing factor to adequate ANC attendance. Strengthened and focused efforts are needed where early ANC initiation and subsequent adequate ANC attendance remain sub-optimal. So, a need to focus on other regions in Tanzania to promote early ANC initiation and subsequently lead to an increase in the number of women attaining adequate ANC. 
Table 4 Decomposition of changes in adequate antenatal care visits 2010 to 2016

\begin{tabular}{|c|c|c|c|c|c|c|}
\hline \multirow[t]{2}{*}{ Characteristics } & \multicolumn{3}{|c|}{ Differences in population structure (E) } & \multicolumn{3}{|c|}{ Differences in coefficients (C) } \\
\hline & Coefficient & $\%$ & $p$-value & Coefficient & $\%$ & $p$-value \\
\hline \multicolumn{7}{|l|}{ Age at delivery (in years) } \\
\hline 15-19 & 1.0 & & & 1.0 & & \\
\hline 20-24 & -0.0014 & -1.7 & 0.138 & -0.010 & -12.2 & 0.209 \\
\hline $25-29$ & -0.0002 & -0.2 & 0.252 & -0.009 & -11.4 & 0.255 \\
\hline $30-34$ & 0.0002 & 0.2 & 0.009 & -0.011 & -13.1 & 0.116 \\
\hline $35+$ & 0.001 & 1.2 & 0.006 & -0.001 & -1.6 & 0.875 \\
\hline \multicolumn{7}{|l|}{ Zones } \\
\hline Western zone & 1.0 & & & 1.0 & & \\
\hline Northern zone & -0.0005 & -6.2 & $<0.001$ & 0.0013 & 1.6 & 0.785 \\
\hline Central zone & -0.0006 & -0.8 & $<0.001$ & 0.0080 & 9.9 & 0.113 \\
\hline Southern Highlands & -0.0028 & -3.5 & 0.006 & 0.0030 & 3.7 & 0.385 \\
\hline Southern zone & -0.0017 & -2.2 & 0.004 & 0.0024 & 2.9 & 0.374 \\
\hline Southwest Highlands & -0.0016 & -0.2 & 0.013 & 0.0173 & 21.4 & 0.001 \\
\hline Lake Zone & 0.0026 & 3.2 & $<0.001$ & 0.0126 & 15.6 & 0.239 \\
\hline Eastern zone & 0.0108 & 13.4 & $<0.001$ & 0.0053 & 6.6 & 0.303 \\
\hline Zanzibar & -0.0003 & -0.4 & $<0.001$ & 0.0011 & 1.4 & 0.333 \\
\hline \multicolumn{7}{|l|}{ Highest level of education } \\
\hline No formal education & 1.0 & & & 1.0 & & \\
\hline Primary education & -0.0011 & -1.3 & 0.324 & -0.014 & -17.6 & 0.356 \\
\hline Secondary and above & 0.0063 & 7.1 & 0.073 & -0.002 & -2.4 & 0.367 \\
\hline \multicolumn{7}{|l|}{ Parity } \\
\hline 1 child & 1.0 & & & 1.0 & & \\
\hline 2-3 children & 0.0003 & 0.4 & 0.009 & -0.078 & -9.6 & 0.378 \\
\hline 4-5 children & 0.0025 & 3.1 & 0.001 & -0.008 & -0.2 & 0.488 \\
\hline $6+$ children & 0.0023 & 2.8 & $<0.001$ & -0.004 & -4.8 & 0.866 \\
\hline \multicolumn{7}{|l|}{ Wealth index } \\
\hline Poorest & 1.0 & & & 1.0 & & \\
\hline Poorer & -0.0003 & -0.4 & 0.645 & 0.0051 & 6.3 & 0.419 \\
\hline Middle & -0.0008 & -0.9 & 0.3 & 0.0017 & 2.1 & 0.761 \\
\hline Richer & -0.0022 & -2.7 & $<0.001$ & 0.0044 & 5.5 & 0.428 \\
\hline Richest & 0.0028 & 3.4 & 0.018 & 0.0087 & 10.7 & 0.122 \\
\hline \multicolumn{7}{|c|}{ Decision on respondent's health } \\
\hline Respondent alone & 1.0 & & & 1.0 & & \\
\hline Respondent \& partner & 0.0042 & 5.2 & 0.255 & 0.0177 & 21.9 & 0.079 \\
\hline Partner alone & 0.0057 & 7.1 & 0.125 & 0.0066 & 8.2 & 0.508 \\
\hline Someone else & -0.0008 & -0.1 & 0.951 & 0.0005 & 0.6 & 0.728 \\
\hline \multicolumn{7}{|l|}{ Desire of last pregnancy } \\
\hline Wanted then & 1.0 & & & 1.0 & & \\
\hline Wanted later & -0.003 & -3.7 & 0.024 & 0.007 & 8.7 & 0.102 \\
\hline Wanted no more & -0.001 & -0.1 & 0.483 & -0.0017 & -2.1 & 0.412 \\
\hline \multicolumn{7}{|l|}{ First ANC initiated } \\
\hline Later than $1^{\text {st }}$ trimester & 1.0 & & & 1.0 & & \\
\hline Within $1^{\text {st }}$ trimester & 0.0408 & 50.5 & $<0.001$ & -0.0016 & -2.0 & 0.459 \\
\hline \multicolumn{7}{|l|}{ Frequency of watching TV } \\
\hline Not at all & 1.0 & & & 1.0 & & \\
\hline Less than once a week & 0.0007 & -0.9 & 0.821 & -0.0016 & -1.9 & 0.542 \\
\hline At least once a week & 0.0024 & 2.9 & 0.122 & -0.0071 & -8.8 & 0.062 \\
\hline Constant & & & & -0.0045 & -5.5 & 0.947 \\
\hline Total & & 66.2 & $<0.001$ & & 33.8 & 0.004 \\
\hline
\end{tabular}




\section{Conclusion}

The results of this study indicate that adequate ANC attendance has been declining from 2004 to 2010 but a gradual increase has been observed in 2016. ANC initiation within the first twelve weeks of pregnancy has greatly contributed to the recent observed increased proportion of pregnant women who attained four or more ANC visits in Tanzania.

\section{Study limitation and strength}

The study has successfully identified factors associated with changes in adequate ANC visits among pregnant women in Tanzania. With this, it is possible to reallocate the limited resources in Tanzania to focus on the factors that have shown to have a great contribution and influence on attaining adequate ANC visits among pregnant women in Tanzania. We have used nationally representative data which makes the study findings generalizable to the entire nation.

Data on the quality of ANC service was not analyzed in this study, we failed to establish its effect on adequate ANC attendance. Also, the analysis did not include biomedical data on HIV status which could have overestimated the number of ANC visits as HIV-positive women attend ANC on monthly basis. Also, the study is prone to social desirability bias as the women are aware of the recommended minimum ANC visits, which could have overestimated the effects. This study is a Crossectional study, no temporal relationship can be established.

\section{Recommendation}

Basing on the findings obtained, we would recommend the MOHCDGEC and implementing partners to put more effort on promoting the first ANC visit to be initiated within the first twelve weeks of pregnancy. This should be done hand in hand with providing mass education on the importance of ANC visits and why a pregnant women should adhere to the ANC comprehensive package. Intervention should be done at facility and community level. This will enable mothers and the communities to be informed on the pivotal role of ANC services as far as the safety of the mother and child is concerned and ensure continuous support from their families. Regional focused interventions such as 'Wazazi na Mwana Campaign' should be rolled out in regions with low uptake of ANC services. Further research to assess the quality of ANC services offered as it may have contributed to the changes observed and sub-optimal ANC attendance while we have a $98 \%$ coverage of at least one ANC visit among pregnant women in Tanzania.

\section{Abbreviations}

ANC: Antenatal care; APR: Adjusted Prevalence Ratios; FANC: Focused Antenatal Care; LBW: Low Birth Weight; MDG: Millennium Development Goals; MMR:
Maternal Mortality Ratio; SDG: Sustainable Development Goals; TDHS: Tanzania Demographic and Health Survey; WHO: World Health Organization.

\section{Acknowledgments}

We would like to thank the Kilimanjaro Christian Medical University college and Sub-Saharan Africa Consortium for Advanced Biostatistics Training program for making it possible to carry out this study. And the Demographic and Health Survey Program granted access to use the TDHS data for this study. My sincere gratitude to the Department of Epidemiology and Biostatistics at Kilimanjaro Christian Medical University College and Epidemiology and classmates for their continuous support.

\section{Authors' contributions}

Concept development and study design: EK, JT, JR; Data acquisition: EK; Supervision of the

study: JT, JR; Data analysis and statistical support: EK, JT, JR; critically revised the manuscript: EK,

JT, JR; All authors read and finally approved the manuscript draft for publication.

\section{Funding}

This work was supported through the DELTAS Africa Initiative Grant No.107754/Z/15/ZDELTASAfrica SSACAB. The DELTAS Africa Initiative is an independent funding scheme of the African Academy of Sciences (AAS) 's Alliance for Accelerating Excellence in Science in Africa (AESA) and supported by the New Partnership for Africa's Development Planning and Coordinating Agency (NEPAD Agency) with funding from the Wellcome Trust (Grant No. 107754/Z/15/Z) and the UK government. The views expressed in this publication are those of the author(s) and not necessarily those of AAS, NEPAD Agency, Wellcome Trust, the UK government.

The funding made it possible for me to undertake my postgraduate studies in which this research was done as part of requirements for the fulfilment of the postgraduate studies.

\section{Availability of data and materials}

Data and material will be available upon request from the corresponding author with authorization form demographic and health survey program, measure DHS.

\section{Declarations}

Ethics approval and consent to participate

Ethical approval to conduct the study was obtained from the Kilimanjaro Christian Medical University college research ethical committee. The ethical approval number granted was 2389.

Since this study used the Tanzania Demographic and Health Survey data, permission to access the datasets was sought form Demographic and Health Survey Program. Datasets used are openly accessible at DHS measure website; http://dhsprogram.com/data/available-datasets.cfm.

Consent for publication

Not applicable.

\section{Competing interests}

The authors declare that they have no competing interests.

\section{Author details}

${ }^{1}$ Department of Epidemiology and Biostatistics, Institute of Public Health, Kilimanjaro Christian Medical University College (KCMUCO), P.O Box 2240, Kilimanjaro, Tanzania. ${ }^{2}$ London School of Hygiene and Tropical Medicine (LSTM), London, UK.

Received: 28 April 2020 Accepted: 18 December 2021

Published online: 07 January 2022

References

1. WHO. The World Health Report 2005: make every mother and child count The World Health Report 2005: World Heal Rep; 2005. 
2. World Health Organization. Maternal mortality fact sheet. Dept Reprod Heal Res World Heal Organ. 2014;4.

3. Downe S, Finlayson K, Tunçalp, Metin Gülmezoglu A. What matters to women: a systematic scoping review to identify the processes and outcomes of antenatal care provision that are important to healthy pregnant women. BJOG. 2016;123(4):529-39.

4. Haftu A, Hagos H, Mehari MAB, Brhane G. Pregnant women adherence level to antenatal care visit and its effect on perinatal outcome among mothers in Tigray Public Health institutions, 2017 : cohort study. BMC Res Notes. 2018:1-6. https://doi.org/10.1186/s13104-018-3987-0.

5. Ntui AN, Jolly PE, Carson A, Turpin CA, Zhang K, Berhanu T, et al. Antenatal care attendance, a surrogate for pregnancy outcome? The case of Kumasi, Ghan. Matern Child Heal J. 2016;18(5):1085-94.

6. Gupta R, Talukdar B. Frequency and timing of antenatal care visits and its impact on neonatal mortality in EAG States of India. J Neonatal Biol. 2017;06(03) Available from: https://www.omicsonline.org/open-access/ frequency-and-timing-of-antenatal-care-visits-and-its-impact-on-neona tal-mortality-in-eag-states-of-india-2167-0897-1000263-97029.html.

7. Blencowe H, Cousens S, Jassir FB, Say L, Chou D, Mathers C, et al. National, regional, and worldwide estimates of stillbirth rates in 2015, with trends from 2000: A systematic analysis. Lancet Glob Heal. 2016;4(2):e98-108. https://doi.org/10.1016/S2214-109X(15)00275-2.

8. Govender T, Reddy P, Ghuman S. Obstetric outcomes and antenatal access among adolescent pregnancies in KwaZulu-Natal, South Africa Obstetric outcomes and antenatal access among adolescent pregnancies in KwaZulu-Natal, South Africa. South African Fam Pract. 2018;60(1):1-7. https://doi.org/10.1080/20786190.2017.1333783

9. Organization world health. WHO Recommendation on Antenatal care for positive pregnancy experience. WHO Recomm Antenatal care Posit pregnancy Exp. 2016;152. Available from: http://apps.who.int/iris/bitst ream/10665/250796/1/9789241549912-eng.pdf.

10. World Health Organization (WHO). WHO Recommendations on Antenatal Care for a Positive Pregnancy Experience: Summary. Who. 2018;10(January):176.

11. Kearns A, Hurst T, Caglia Jacquelyn LA. Focused antenatal care in Tanzania. Women Heal Initiat. 2014;(July):1-13 Available from: http://www. mhtf.org/wp-content/uploads/sites/32/2014/09/HSPH-Tanzania5.pdf.

12. UNICEF. ANTENATAL CARE [Internet]. Available from: https://data.unicef. org/topic/maternal-health/antenatal-care/.

13. Ministry of Health, Community Development, Gender E and CM, Ministry of Health, National Bureau of Statistics, Office of Chief Government Statistician, ICF. Tanzania demographic and health survey and malaria indicator survey 2015-2016. 2016; Available from: https://dhsprogram.com/pubs/ pdf/FR321/FR321.pdf.

14. Evaluation A, Safe N, Campaign M. An evaluation of Tanzania 's national safe motherhood campaign an evaluation of Tanzania 's national safe motherhood campaign. 2014;(September).

15. Exavery A, Kanté AM, Hingora A, Mbaruku G, Pemba S, Phillips JF. How mistimed and unwanted pregnancies affect timing of antenatal care initiation in three districts in Tanzania. BMC Pregnancy Childbirth. 2013;13:1-11

16. Bliss KE, Streifel C. Targeting big results in maternal, neonatal, and child health. 2015;(May).

17. Teplitskaya AL, Dutta A, Saint-firmin P, Wang Z. Maternal Health Services in Tanzania: determinants of use and related financial barriers from 201516 survey data. 2018;(May).

18. Titaley CR, Dibley MJ, Roberts CL. Factors associated with underutilization of antenatal care services in Indonesia: Results of Indonesia Demographic and Health Survey 2002/2003 and 2007. BMC Public Health. 2010;10.

19. Joshi C, Torvaldsen S, Hodgson R, Hayen A. Factors associated with the use and quality of antenatal care in Nepal : a population-based study using the demographic and health survey data; 2014. p. 1-11.

20. Andersen RM. Revisiting the behavioral model and access to medical care: does it matter? J Health Soc Behav. 1995;36(1):1-10.

21. Thomas K. RWI : Discussion papers; 2006.

22. Mavromaras KG. No 70 Male-female labour market participation and wage differentials in Greece Male-female labour market participation and wage differentials in Greece. 1999;(70):1-39.

23. Ospino CG. La descomposición salarial de Oaxaca- Blinder : Métodos, críticas y aplicaciones. Una revisión de la literatura. 2011;237-74.
24. Saad-Haddad G, DeJong J, Terreri N, Restrepo-Méndez MC, Perin J, Vaz $L$, et al. Patterns and determinants of antenatal care utilization: analysis of national survey data in seven countdown countries. J Glob Health. 2016;6(1) Available from: http://www.jogh.org/documents/issue201601/ jogh-06-010404.pdf.

25. Gupta S, Yamada G, Mpembeni R, Frumence G, Callaghan-Koru JA, Stevenson $\mathrm{R}$, et al. Factors associated with four or more antenatal care visits and its decline among pregnant women in Tanzania between 1999 and 2010. PLoS One. 2014;9(7)

26. Provision S, Survey A. Service provision assessment survey 2006 (TSPA). 2006;2006.

27. Nyamtema AS, Jong AB, Urassa DP, Hagen JP, van Roosmalen J. The quality of antenatal care in rural Tanzania: what is behind the number of visits? BMC Pregnancy Childbirth. 2012;12(1):1 Available from: ???

28. Magoma M, Requejo J, Merialdi M, Campbell OMR, Cousens S, Filippi V. How much time is available for antenatal care consultations? Assessment of the quality of care in rural Tanzania. BMC Pregnancy Childbirth. 2011;11(1):64 Available from: http://www.biomedcentral.com/14712393/11/64.

29. MoHSW, Africare, Plan International, JHPIEGO. WAZAZI NA MWANA PROJECT BRIEF. 2015. Available from: http://www.africare.org/wp-conte nt/uploads/2014/04/Tanz_Project-Brief_Wazazi-na-Mwana_web.pdf.

30. Moshi FV, Kibusi SM, Fabian F. The effectiveness of community-based continuous training on promoting positive behaviors towards birth preparedness, male involvement, and maternal services utilization among expecting couples in rukwa, Tanzania: a theory of planned behavior quasi-experim. J Environ Public Health. 2018;2018.

\section{Publisher's Note}

Springer Nature remains neutral with regard to jurisdictional claims in published maps and institutional affiliations.

Ready to submit your research? Choose BMC and benefit from:

- fast, convenient online submission

- thorough peer review by experienced researchers in your field

- rapid publication on acceptance

- support for research data, including large and complex data types

- gold Open Access which fosters wider collaboration and increased citations

- maximum visibility for your research: over 100M website views per year

At BMC, research is always in progress.

Learn more biomedcentral.com/submissions 